\title{
Why the way we look at things in reproductive medicine is changing
}

\author{
David F. Albertini ${ }^{1}$
}

Published online: 11 November 2017

(C) Springer Science+Business Media, LLC 2017

Perceptions in biology and medicine have landed squarely in a high-resolution landscape that seemingly has few boundaries. Progress in biomedical imaging and molecular diagnostics has taken us beyond observational constraints of the photograph or ultrasound readout in probing the inner workings of cells and tissues that make up the reproductive tract. With archival force, the imaging tools and their perceptual alignment with disciplines of molecular biology, high-speed data processing, and bioinformatics converge into a new reality of biological systems prompting a new set of questions within which our understanding of basic reproductive events must be reinterpreted. One need not look far beyond the recent set of publications on gene editing in human embryos (see below) to contemplate how our protocols and methods in human ARTs will be modified to accommodate the insights and discoveries looming on the horizon. And beware, embryologists-imagining a world of standardization and automation is not so farfetched given the advances in bioengineering and microfluidics entering other diagnostic and treatment programs.

Observational and original investigative rigor in past years was measured by guess work, intuition honed by experience (repeating experiments), and technological bravado yielding the data at hand. Much of that data was visualizable and relatable to tangible tidbits of information.

A case in point is the chromosome.

Since the days of electron microscopy, chromosomes in eukaryotes have evolved in substance and form as the limits

David F. Albertini

eicjarg@gmail.com

1 The Center for Human Reproduction, New York, NY, USA of optical resolution have been surpassed using microscopes capable of integrating massive data sets in four dimensions, allowing mapping of gene interactions with the spatial precision of GPS. With this perspective obtains a very different view of the chromosome. Now we speak of gene bodies, chromatin territories, physical dynamism leaving in the dust remnants of conventional wisdom overshadowed by epigenetics. Has reproductive medicine adapted to changes in thinking about the organization and function of eukaryotic genomes? I think not.

Looking beyond core chromatin structure in these days of CrisprCas9 evokes satisfaction and wonderment. Satisfaction from perceptions formed decades ago such that traditional technologies withstand the test of time, at least in some instances (yes, the nucleosome still merits attention). Wonderment at how the complexity and diversity of RNAs now dwarfs our old gene-mRNA-protein oneness mindset. So where should we aim our curiosity in reproductive medicine if we are truly intent on deepening our understanding in human biology? Are we seeing more? Or less? We continue the search for the ideal gamete or embryo - those presaging the birth of a healthy child - but is our approach becoming more inferential and less visible in the literal sense?

A humble attempt to address such an irony is presented on our cover this month. Little known to most, but engrained into the roots of oology-oocyte cytology to be exact, is a structure common to the oocytes of nearly all metazoan organisms: the Balbiani body (BB). Viewed as esoterica for years, this key component of the oocyte has come into focus once again owing to its suspected role in the inheritance of mitochondria and their genomes. As a major part of the maternal dowry, the $\mathrm{BB}$ and its organellar entourage take center stage in the new world of human ARTs, given ongoing interest in the origins of mitochondrial disease and potential therapeutic approaches to 
eliminate such human disorders. For an updated account of the $\mathrm{BB}$, our audience is directed to the review article leading off this issue.

Our cover image depicts an abstracted version of the BB complements of computer-generated 3-dimensional technology (Selection of mitochondria in female germline cells: is Balbiani body implicated in this process? https://doi.org/10. 1007/s10815-017-1006). Unlike sperm, selecting the highquality oocyte for embryo production remains an intractable problem given the many dysmorphisms a human oocyte assumes and the inadequacy of our discretions when it comes to predicting live birth outcomes [1]. Ironically, the BB was first described in the human oocyte 50 years ago [2], and yet its importance with respect to teasing apart functional relevance during aging in the human ovary was far more recent [3]. And for once, we can safely conclude that something in science (certainly well within the realm of reproductive biology) awaited the rediscovery of the BB in mice [4]. So why the big deal about the BB? As luck would have it, although from a different animal model system, the BB seems to be held together by a class of proteins resembling amyloid, the distinctive components of tangles that are believed to be causative in the progression of certain age-related neurological diseases [5].

The point here is that knowing something of the history of oocyte biology, in this case when technology was relatively simple, can open doors for contemporary research into the most vexing of reproductive disorders - ovarian aging. And with the evolution of fertility preservation technology and applications coming to the forefront, studies like this will, using conventional tools and perspectives, be drawn upon to broaden our understating of gonadal development and function.

As such, we at JARG continue to maintain our commitment to deliver the latest advances in fertility preservation. Ranging from new devices for cryopreservation, to practical application to an ever broader range of patients in need of this specialized care (Fertility preservation for trans men: frozen-thawed in vitro matured oocytes collected at the time of ovarian tissue processing exhibit normal meiotic spindles https://doi.org/10. 1007/s10815-017-0976), this is a rapidly developing field that will continue to serve populations confronted by the most basic of guiding principles in human reproduction.

Perhaps we should all take pause with the recent papers on gene editing in human embryos, a milestone in human medicine that is likely to affect the practice of ARTs [6]. Notable also that only weeks later, this technology was used not to effect a corrective influence on a mutant gene but to explore a fundamental aspect in mammalian embryology having to do with how the various cell lineages of the early embryo their future identities [7]. The gene editing approach is already revealing how little we know about the earliest genetic and epigenetic events that initiate development of human embryos, raising to new heights evidence of intra- and interchromosomal events far more complex than conventional thinking currently permits (https://www.biorxiv.org/content/early/ 2017/08/28/181255).

And finally, when discourse reaches the polarizing base upon which new technology like gene editing has imprinted on the practice of human ARTs (not unlike that being experienced in the political landscapes around the world today), the high road better traveled may be to share with our patients and hopeful consumers how little we know, and that as in the past we will have to wait for the test of time to give direction and promise in emerging technologies capable of treating infertility and fostering access to health care for family building.

\section{References}

1. Dal Canto M, Guglielmo MC, Mignini Renzini M, Fadini R, Moutier C, Merola M, et al. Dysmorphic patterns are associated with cytoskeletal alterations in human oocytes. Hum Reprod. 2017;32(4):750-7.

2. Hertig AT. The primary human oocyte: some observations on the fine structure of Balbiani's vitelline body and the origin of the annulate lamellae. Am J Anat. 1968;122(1):107-37.

3. Albamonte MI, Albamonte MS, Stella I, Zuccardi L, Vitullo AD. The infant and pubertal human ovary: Balbiani's body-associated VASA expression, immunohistochemical detection of apoptosisrelated BCL2 and BAX proteins, and DNA fragmentation. Hum Reprod. 2013;28(3):698-706.

4. Pepling ME, Wilhelm JE, O'Hara AL, Gephardt GW, Spradling AC. Mouse oocytes within germ cell cysts and primordial follicles contain a Balbiani body. PNAS. 2007;104(1):187-92.

5. Boke E, Ruer M, Wuhr M, Coughlin M, Lemaitre R, Gygi SP, et al. Amyloid-like self-assembly of a cellular compartment. Cell. 2016;166(3):637-50.

6. Ma H, Marti-Gutierrez N, Park SW, Wu J, Lee Y, Suzuki K, et al. Correction of a pathogenic gene mutation in human embryos. Nature. 2017;548(7668):413-9.

7. Fogarty NME, McCarthy A, Snijders KE, Powell BE, Kubikova N, Blakeley P, et al. Genome editing reveals a role for OCT4 in human embryogenesis. Nature. 2017;550:67-73. https://doi.org/10.1038/ nature24033. 